\title{
Applications of Ultrasound in Meat Processing Technology: A Review
}

\author{
Evans Frimpong Boateng*, Mustapha Muhammad Nasiru \\ College of Food Science and Technology, Nanjing Agricultural University, China
}

Copyright $(2019$ by authors, all rights reserved. Authors agree that this article remains permanently open access under the terms of the Creative Commons Attribution License 4.0 International License

\begin{abstract}
In the replacement of traditional techniques (cutting, degassing, meat tenderization among others) and assisting of traditional techniques (brining, freezing and thawing, filtration among others), ultrasound has been effectively utilized in various areas of food technology and yet further research demand is recommended in terms of optimization of process conditions (scaling up of ultrasound equipment) and the enhancement of existing processes potential for efficient use in analyzing and modifying food and food products as well as industrial use. Few other technologies combined with ultrasound have shown potentials of effectively controlling food microorganisms. Hence, contribution to the advancements in food safety, processing and preservation owing to these potential advantages of ultrasound, summaries of ultrasound idea and utilization in food industry meat technology longstanding application significant effect are reviewed.
\end{abstract}

Keywords Ultrasound, Cavitation, Low Intensity, High Intensity and Meat

\section{Introduction}

In recent times, food industries of developing countries in the wake of effectively preserving food are implementing hurdle technology. To increase food, save it from microorganisms and prolong shelf-life of energy delicate, nutritional, and sensory characteristics, the use of ultrasound is of great importance [1]. High power ultrasound gives a secondary choice to ordinary food preservation know-how, as indicated by [2] and multiple interest of ultrasound application potentials have been realised in recent times. Again, efficient preservation techniques of food based on important hurdles, physiology and food microorganism's behaviour, have been reviewed by [3] since hurdle technology prospects remain as a food renovation approach emergence in food industries. The distinction between non-thermal method (ultrasound) and thermal processes (pasteurization and sterilization) in food processing and preservation includes, the parameters necessary for a higher quality food to be achieved for consumption, and the negative effect that occurs on food products to some extent under thermal food process. Therefore, for processing and preserving purposes, ultrasound technology is held in high regards due to its superior properties. High hydrostatic pressure, pulsed electric fields, ultrasound, ozone, pulsed light, and ultraviolet light, are variety of researched potential/novel alternative techniques in the past decade, yet, high-intensity ultrasound has captivated substantial enthusiasm for food storage utilization [4]. Quality control, extraction, meat processing, crystallisation, performance alteration, separation and deactivation of microbes are the applicable fields in food and bioprocessing that have utilized ultrasound in recent years likewise, the accomplishment of ultrasonic approach in the guidance of food emulsion [5, 6]. Also, ultrasound adaptation has established to be an efficacious strategy which intensified the flux in ultrafiltration or microfiltration techniques and fouled membranes cleansing improvement [6] as membrane technological know-how is utilized in treating liquid sewerage streams and water purification as a verified technology in food and dairy enterprise [7]. More so, quality standards including tenderness, protein extraction, gelatin, meat products restructuring, restructured products salt reduction and maximising cooking yield to ascertain carcass distinguishing quality in meat processing currently utilizes ultrasound technology as swift, comparatively inexpensive, easy and tried and true alternative processing means [8]. In spite of these benefits obtained from ultrasound in curbing food safety challenges in the food industry in terms of high quality and shelf-life extension among others, ultrasound technology types and ultrasound technology in meat processing and preservation remains a key subject of concern in the meat industries in terms of enhancing meat distinguished characteristics. Hence, a review of ultrasound ideas and significant effect was summarized on meat technology. 


\section{Ultrasound Physics}

Ultrasound as an energy form utilizes pressure waves (longitudinal mechanical wave) with a one-dimensional propagation and vibration frequency of $20 \mathrm{kHz}$ or more above the audible/hearing sound limit of humans. Ultrasound speed is dependent on the acoustic properties of medium resulting in a greater propagation of sound in solids than in liquids as well as higher in liquids than in gases. A traveling sound produces waves of compression and rarefaction of materials through a medium of cavities and or bubbles formation. High temperature and pressure are released in effect of cavities growth of ultrasound subsequent cycles instability and collapsing in an ultrasound system $[2,9,10,11]$. Ideally, ultrasound as an acoustic energy of a non-ionizing, non-intrusive, and non-contaminating form of mechanical energy inside an organic material that excite these natural materials and tissues on micro and a macro index positively by affecting food quality and safety promotion increment in food processing due to the unstable and collapsing mechanism of sound transmitting through a sonicated medium [2, 12, 13]. At low intensity (amplitude), pressure wave instigates motion compounding inside fluid (acoustic streaming) whiles local pressure at the dilation phase of cycle drops beneath vapour pressure of the liquid generated tiny effervescence produced from the present gas nuclei within the fluid to grow at higher intensities [14]. Cavitation seeks to be the very vital effect in high power ultrasonics as compression and deflexion of medium particles and the globule fall over resultant [15]. Micro-streaming is also the main mechanism for ultrasonic degassing which is referred to as bubble conveyance action and development at nodes and anti-nodes [14]. On the basis of energy amount let out by cavitation, the phenomenon relies on bubble generation kinetics and it collapses, which purposely seem vital for food processing as heat is generated on the basis of ultrasound employment and cognate cavitation (gravitational collapse of gas bubbles) induced by speedy heating alteration to $5500^{\circ} \mathrm{C}$ and pressure rise to $50 \mathrm{Mpa}$ $[14,16]$. On the basis of analysis and quality control, food processing industry applies ultrasound in operations based on the frequency range. Low-intensity ultrasound is the same as low power/low energy because, it utilizes frequencies above $100 \mathrm{kHz}$ at $<1 \mathrm{~W} / \mathrm{cm}^{2}$ intensities to result in high quality and safe food material during processing and storage, and higher-intensity ultrasound at incidence of 20 to $100 \mathrm{kHz}$, is named as high energy or high power and utilizes higher than $1 \mathrm{~W} / \mathrm{cm}^{2}$ intensities. Also, it has the cognition to prompt cavitation, applied in food processing to demobilise microorganisms and bring forth the physical, chemical/biochemical attributes of foods imputable to disruptive efficiency, thus, food properties control and quality enhancement [9, 17]. Low-intensity and high-intensity ultrasounds are the two ultrasound classifications and can be referred to as high frequency and low frequency respectively. Both categories of ultrasound have resulted in the effective application in variable fields most especially, food processing and safety-related sectors. Ultrasound nature (e.g. frequency, intensity), product properties (e.g. viscosity, surface tension) and ambient conditions (e.g. temperature, pressure) are dependable factors associated with cavitation effect of ultrasound during sonication process [18]. In sonication treatment process, two divisions of bubbles forms produced on structural basis include: - (a) non-linear; generating large globule clouds with balance scale in course of pressure cycles known to be steady cavitations bubbles, (b) non-constant; swiftly fallen out and breaking down into smaller bubbles referred to as internal (transient) cavitations bubbles [19]. High power ultrasound potential for micro-organisms inactivation in meat and meat products is popular presently [20], hence, straightforward introduction to products, coupling ultrasound with a device and ultrasound bath (submerging) are the three methods of applying ultrasound technology [19].

\section{Ultrasound in Food Analysis}

In as a great deal as food industries craves for advanced analytical technologies/techniques for sophisticated food materials and food composition/properties monitoring during processing so as ultrasound application over some 60 years ago utilized low-intensity ultrasound in a non-destructive utilization manner to provide details about physiochemical properties (flow rate, composition, structure and physical state), that is small ultrasound wave yielded no physical or chemical changes via material qualities wave pass [18, 21]. On the different hand, high-intensity ultrasound changes chemical/physical properties (enzyme inhibition, cell disruption, chemical reactions, modify crystallization, tenderize meat, emulsion generation) of foods [21, 22]. Physical state, structure and composition food properties are of interest to food scientists hence, velocity, attenuation coefficient and acoustic impedance are measurement parameters utilized by low-intensity ultrasound application [21]. Based on several scientific research of ultrasound in the past years, full potentials of ultrasound have been realised in numerous field applications. Naturally, some animals such as dolphin and bats apply ultrasound in navigation and hunting respectively based on back-scattering sound waves mechanism [9], so as certain marine animals stun victims prior to capture by utilizing high- intensity pulses of ultrasound [21]. In food processing ultrasound has supported genetic improvement programmes for livestock as well as raw and fermented meat products, fish and poultry composition evaluation (low-intensity ultrasound), whilst, high-intensity ultrasound has shown to spark off the immobilizes enzymes through rising enzymes to substrate proportion [9, 23]. Chemical, cosmetic, textile, polymer, 
and petrochemical industries in current times started to apply ultrasound in the food industry for items such as ketchup, mayonnaise, vegetable and fruit juice production $[24,25]$. Numerous versatile and profitable merits obtained from ultrasonic technology in the food industry further include, non-destructive analytical method assessment of opaque fluid properties and foreign materials identification in food via food container walls and for investigating physiochemical and structural qualities of fluid foods by combining low power ultrasound with spectroscopy and nuclear magnetic resonance (NMR) [26, 27]. Fruits and vegetables qualities have been enhanced by utilizing ultrasound in pre and post-harvest periods. Storage and shelf-life, maturity and sugar concentration in fruit tissue correlated positively with firmness among plum fruits as investigated by [28] in quantifying ultrasound attenuation in plum fruit tissue, likewise tomato monitoring and defective potatoes quality evaluation [28, 29, 30]. Living cells activity stimulation and food surface cleaning apply low-intensity ultrasound [31]. Sensors, filters, substrates, reactors, catalysers and heat exchangers among other disciplines combining ultrasound and chemical treatment is applicable in surface cleaning on the merit of attenuate chemical imbibition, decreased of direct worker contact with unsafe cleaning chemicals/substances, meliorate cleaning speed, cleansing uniformity. Hence, to achieve a uniform cleaning by entering all crevices, automatic activeness and control savings linked to energy costs, labour and floor space, ultrasonic activity is used [32]. Food resources from cereals products (bread, biscuits, breakfast bars among others) which applies rheological techniques revealed to be effective in on-line dough-based products quality control by combining Ultrasound factors (velocity and attenuation) and conventional rheology techniques [33]. Compressibility in batters when monitored by scaling acoustic impedance of batter and batter consistency [34, 35]. Fat within milk homogenisation from monitoring attenuation of an ultrasound pulse, edible fats and oil and crystallization and melting in dispersed emulsion droplets are examples within food technology that velocity and attenuation measurement of ultrasound been applied [18]. Ideally, sonication potentials are of wider range application in food technology from bacterial destruction ([micro-organisms] micromechanical and chemical antimicrobial mechanisms of ultrasound) [36], to fat emulsion products (margarine, butter, chocolate, shortenings and creams). From effervescent food (ice cream, whipped cream, confectionary, bread dough and desserts) to inactivation of enzymatic extravasation reckoning on ultrasound intensity[9]. Food freezing, thawing of frozen foods, drying, sterilization and extraction uses ultrasound or a combination of ultrasound and other technology models such as ultrasound food conservation methods (Manosonication: ultrasound and pressure amalgamation (MS)., Thermosonication: combination of ultrasound and heat (TS).,
Manothermosonication: combination of ultrasound, pressure and heat (MTS)) to generate assured food quality. More efficacious mixing and small-mixing, speed energy and bulk transfer, reduced thermal and concentration gradients, reduced temperature, selective extraction, decreased equipment size, faster response to process extraction control, faster beginning, accrued production, and execution of process steps are benefits obtained from using ultrasound in food processing [32].

\section{Ultrasound in Meat Technology}

Skeletal muscle and its interrelated tissues obtained from mammalian, avian, reptilian, amphibian and aquatic species harvested and eaten by man, as well as edible offal (organs and non-skeletal muscle tissues) are regarded as meat [37]. Consumption of meat has a positive economic impact due to its nutritional composition, as a part of well-balanced diets; hence its high demand can be traced since the prehistoric era [38]. Ultrasonic technology is reported to be prudent in meat technology, in which its emergence began in the 1950s in evaluating live cattle fat and muscle [2]. Among the meat products, the use of real-time ultrasound has largely been applied in body and carcass chemical transcription estimation. Intra-muscular fat percentage, (sheep) carcass traits, reflection prototypes of tissues such as muscle, fat and internal organs in live animals has been helpful in genetic improvement through low-intensity ultrasound adaptation in meat technology when reviewed by [9]. Tenderness of meat leads to consumer's acceptance since inconsistent tenderness is the major yield problem in the meat sector, because consumers seem unsatisfied with the meat quality, therefore, a synergistic effect of heat and ultrasound revealed tenderising benefit on meat [39]. Ultrasound technique on meat compels membrane disruption to increase meat tenderness either forthwith, via the physical weakening of muscle make-up, or indirect, by proteolysis stimulation either by release of cathepsins from lysosomes and/or of $\mathrm{Ca}^{++}$ions so that calpains may be activated, whilst others stated no effect or influence [18, 40]. The impact of ultrasound during meat brining is influenced by ultrasonic intensity or frequency [41], as well as effective diffusivity of $\mathrm{NaCl}$, and moisture improved with the application of ultrasound [42]. More so, ultrasound effectively reduced the salting time in meat tenderness, flavour and shelf-life improvement analysis, as marination is highly regarded in meat processing. Hence, intensity and frequency of ultrasound are revealed to be the prime parameters needed to be factored in achieving effective marination in meat processing [20, 43]. Moreover, ultrasound serves as anti-microbial tool in meat technology, and has delivered great potentials to meat industries in improving meat quality. However, questions keep popping up for research due to some inconsistencies in reported results of 
ultra-sonication application in the meat sector. Water holding capacity (WHC) of meat treated under ultrasound also shows variable results in processing and preserving of meat [2]. The weight of traditional techniques in processing food and misfortunate discernment of new process discipline (ultrasound) by food professionals are contributors to the reluctant utilization of ultra-sonication technology among many companies [44]. Measuring the ultrasound energy that transfers to medium influence ultrasound intensity during application for different test treatments[20]. Also, the exact frequency of ultrasound and the optimal treatment time is needed for a controlled and optimal ultrasound application [45].

\section{Conclusions}

Generally, the sound wave is considered non-toxic, environmentally friendly and safe over other methods of food processing. Presently, numerous research publications indicate the merits of ultra-sonication, solely or combined, to produce safe food for consumers. However, there are some inconsistencies in the earlier reports which give rise to the need for more research on ultrasound due to variations in the effects of ultrasound treatments in various sectors of food technology. Hence, the need for continuous research for best/suitable operating conditions among ultra-sonication is recommended. In the meat sector, traits like oxidative stability, meat colour and sensory characteristics are of great importance during meat ultra-sonication, making high-intensity ultrasound technology to be regarded among growing technologies on cured meat. Utilizing sound energy (changing sound energy to heat) can speed up meat thawing yet yielding no significant differences in microbiological, and chemical properties compared with the meat immersed in water (meat thawed by water). Meat quality is improved by applying ultrasound to reducing meat brining time. Basically, when the dynamics of the sound wave (high than sound detected by human ears) are applied in ultra-sonication physics (mechanical waves: compression and rarefaction) under controlled conditions (ultrasound cavitation) to generate high temperature and pressure by cavitation bubbles, quality food will be yielded based on the desired frequency range utilized. Hence, low-intensity and high-intensity ultrasound, popularly used in food technology, can be regarded as green technology of variable utilization in food industry meat technology.

\section{REFERENCES}

[1] Bhat, R., Kamaruddin, C.N.S.B., Liong, M.T. and Karim, A.A. (2011). Sonication improves kasturi lime (Citrus microcarpa) juice quality. Ultrasonics Sonochemistry, 18:1295-1300.
[2] Alarcon-Rojo, A.D., Carrillo-Lopez, L.M. Reyes-Villagrana, R., Huerta-Jiménez, M. and Garcia-Galicia, I.A. (2018). Ultrasound and meat quality: A Review. Ultrasonics Sonochemistry. ISSN 1350-4177.

[3] Leistner, L. (2000). Review Basic aspects of food preservation by hurdle technology. International Journal of Food Microbiology, 55:181-186.

[4] Sandra N. Guerrero, Mariana Ferrario, Marcela Schenk and Mercedes G. Carrillo, (2017). Hurdle technology using ultrasound for food preservation. Ultrasound: Advances in Food Processing and Preservation- ${ }^{\text {st }}$ Edition, 39-99. ISBN 9780128045817 .

[5] Ashokkumar, M. (2015). Applications of ultrasound in food and bioprocessing. Ultrasonics Sonochemistry, 25:17-23.

[6] Jayani Chandrapala, Christine Oliver, Sandra Kentish, Muthupandian Ashokkumar, (2012). Review ultrasonics in food processing. Ultrasonics Sonochemistry. 19:975-983.

[7] Maskooki, A., Kobayashi, T., Mortazavi, S.A. and Maskooki, A. (2010). Effect of low frequencies and mixed wave of ultrasound and EDTA on flux recovery and cleaning of microfiltration membranes. Separation and Purification Technology, 59:67-73.

[8] Dikeman, M. (2013). Animal growth and empty body composition. In: Kerth, C.R. (Ed.), The Science of Meat Quality. John Wiley \& Sons, Inc., Oxford, UK.

[9] Awad, T.S., Moharram, H.A., Shaltout, O.E., Asker, D. and Youssef, M.M. (2012). Applications of ultrasound in analysis, processing and quality control of food: A review. Food Research International, 48: 410-427.

[10] Seda Ersus Bilek and Fulya Turantaş, (2013). Decontamination efficiency of high power ultrasound in the fruit and vegetable industry, a review. International Journal of Food Microbiology, 166:155-162.

[11] Mason T.J. (1998). Power ultrasound in food processing-The way forward. In: Povey M. J. W, Mason T. J, editors. Ultrasound in Food Processing. Glasgow: Blackie Academic \& Professional; pp 104-124.

[12] Hoover, D.G. (2000). Special Supplement Kinetics of Microbial Inactivation for Alternative Food Processing Technologies (Ultrasound). J. Food Sci. 65:93-95.

[13] Povey M. J. W. and McClements D. J., (1988). Ultrasonics in food engineering. Part 1 . Introduction and experimental methods. J. Food Eng, 8: 217-245.

[14] Leighton, T. (1998). The principles of cavitation. In M. J. W. Povey, \& T. J. Mason (Eds.), Ultrasound in food processing pp.151-178. London: Blackie Academic \& Professional.

[15] Moholkar, V.S., Rekveld, S. and Warmoeskerken, M.M.C.G. (2000). Modeling of the acoustic pressure fields and the distribution of the cavitation phenomena in a dual frequency sonic processor. Ultrasonics, 38:666-670.

[16] Dietrich Knorr, Marco Zenker, Volker Heinz and Dong-Un Lee, (2004). Applications and potential of ultrasonics in food processing. Trends in Food Science \& Technology, 15:261-266.

[17] Piyasena, P., Mohareb, E. and McKellar, R.C. (2003). Inactivation of microbes using ultrasound: a review. 
International Journal of Food Microbiology, 87(3): 207-216.

[18] Zbigniew, Dolatowski, J., Joanna Stadnik and Dariusz Stasiak., (2007). Applications of ultrasound in food technology. Acta Sci. Pol., Technol. Aliment, 6(3): 89-99.

[19] Ishrat Majid, Gulzar Ahmad Nayik and Vikas Nanda. (2015). Ultrasonication and food technology: A review. Cogent Food \& Agriculture, 1:1071022.

[20] Fulya Turantaş, Gülden Başyiğit Kılıç, Birol Kılıç (2015). Ultrasound in the meat industry: General applications and decontamination efficiency. International Journal of Food Microbiology, 198: 59-69.

[21] Julian McClements, D. (1995). Advances in the application of ultrasound in food analysis and processing. Trends in Food Science \& Technology, 6(9):293-299.

[22] Shoh, A. (1988). In Ultrasound: chemical, Biolosical and Physical Effects (Suslick K.S., ed.), pp. 97-122, VCH.

[23] Cárcel, J.A., Benedito, J., Bon, J. and Mulet, A. (2007). High intensity ultrasound effects on meat brining. Meat Sci, 76: 611-619.

[24] Soria, A.C. and Villamiel, M. (2010). Effect of ultrasound on the technological properties and bioactivity of food: a review. Trends Food Sci. Technol, 21: 323-331.

[25] Kuldiloke, J. (2002). Effect of ultrasound, temperature and pressure treatments on enzyme activity and quality indicators of fruit and vegetable juices. (Ph.D. Thesis) Technische Universität Berlin.

[26] McClements, D.J. and Gunasekaran, S. (1997). Ultrasonic characterization of foods and drinks: Principles, methods, and applications. Critical Reviews in Food Science and Nutrition, 37(1): 1-46.

[27] Coupland, J.N. (2004). Low intensity ultrasound. Food Research International, 37(6): 537-543.

[28] Mizrach, A. (2004). Assessing plum fruit quality attributes with an ultrasonic method. Food Research International, 37(6): 627-631.

[29] Mizrach, A. (2007). Non-destructive ultrasonic monitoring of tomato quality during shelf-life storage. Postharvest Biology and Technology, 46(3): 271-274.

[30] Cheng, Y. and Haugh, C.G. (1994). Detecting hollow heart in potatoes using ultrasound. Transactions of the Asae, 37(1): 217-222.

[31] Behrend, O.and Schubert, H. (2001). Influence of hydrostatic pressure and gas content on continuous ultrasound emulsification. Ultrason. Sonochem, 8: 271-276.

[32] Mason, T.J. (2003). Sonochemistry and sonoprocessing: the link, the trends and (probably) the future. Ultrason. Sonochem. 10:175-179.

[33] Ross, K.A., Pyrak-Nolte, L.J. and Campanella, O. H. (2004). The use of ultrasound and shear oscillatory tests to characterize the effect of mixing time on the rheological properties of dough. Food Research International, 37(6): 567-577.

[34] Salazar, J., Turó, A., Chávez, J. A. and GarcIa, M. J. (2004).
Ultrasonic inspection of batters for on-line process monitoring. Ultrasonics, 42(1-9): 155-159.

[35] Gómez, M., Oliete, B., García-Álvarez, J., Ronda, F. and Salazar, J. (2008). Characterization of cake batters by ultrasound measurements. Journal of Food Engineering, 89(4): 408-413.

[36] Yusaf, T. and Al-Juboori, R. A. (2014). Alternative methods of microorganism disruption for agricultural applications. Applied Energy, 114:909-923.

[37] Dennis, Seman L., Dustin, Boler D., Chad, Carr, C., Michael, Dikeman, E., Casey, Owens, M., Jimmy, Keeton, T., Dean, Pringle T., Jeffrey, Sindelar J., Dale, Woerner R., Amilton, de Mello S. and Thomas, Powell H. (2018). Meat Science Lexicon. Meat and Muscle Biology, 2:127-141.

[38] Mahaboubil-Haq, M. and Adzitey, F., (2016). Meat production and consumption in the Wa Municipality of Ghana. International Food Research Journal, 23(3): 1338-1342.

[39] Pagan, R., Mañas, P., Alvarez, I. and Condon, S. (1999). Resistance of Listeria monocytogenes to ultrasonic waves under pressure at sublethal (manosonication) and lethal (manothermosonication) temperatures. Food Microbiology, 16: 139-148.

[40] Pohlman, F.W., Dikeman, M.E. and Zayas J.F. (1997). The effect of low-intensity ultrasound treatment on shear properties, colour stability and shelf life of vacuum packaged beef semitendinosus and biceps femor is muscles. Meat Sci, 45(3): 329-337.

[41] Mulet, A., Ca'rcel, J.A., Sanjua'n, N., and Bon, J. (2003). New food drying technologies. Use of ultrasound. Food Science and Technology International, 9(3): 215-221.

[42] Ozuna, C., Puig, A., García-Pérez, J. V., Mulet, A., and Cárcel, J. A., (2013). Influence of high intensity ultrasound application on mass transport, microstructure and textural properties of pork meat (Longissimus dorsi) brined at different $\mathrm{NaCl}$ concentrations. Journal of Food Engineering, 119:84-93.

[43] Smith D.P (2011). Effect of ultrasonic marination on broiler breast meat quality and Salmonella Contamination Int. J. Poult. Sci., 10 (10): 757-759.

[44] Farid Chemat, Zill-e-Huma, and Muhammed Kamran Khan. (2011). Applications of ultrasound in food technology: Processing, preservation and extraction. Ultrasonics Sonochemistry, 18: 813-835.

[45] Režek Jambrak, A., Lelas, V., Herceg, Z., Badanjak, M., Batur, V. and Muža, M. (2009). Advantages and disadvantages of high power ultrasound application in the dairy industry. Journal for dairy production and processing improvement, 59(4): 287-281. 